\title{
In vivo high-resolution magic angle spinning proton NMR spectroscopy of Drosophila melanogaster flies as a model system to investigate mitochondrial dysfunction in Drosophila GST2 mutants
}

\author{
VALERIA RIGHI ${ }^{1-4}$, YIORGOS APIDIANAKIS ${ }^{4,5}$, NIKOLAOS PSYCHOGIOS ${ }^{1,2,4}$, \\ LAURENCE G. RAHME ${ }^{4,5}$, RONALD G. TOMPKINS ${ }^{4}$ and A. ARIA TZIKA ${ }^{1,2,4}$
}

\begin{abstract}
${ }^{1}$ NMR Surgical Laboratory, Department of Surgery, Massachusetts General Hospital and Shriners Burn Institute, Harvard Medical School; ${ }^{2}$ Athinoula A. Martinos Center of Biomedical Imaging, Department of Radiology, Massachusetts General Hospital, Boston, MA 02114, USA; ${ }^{3}$ Department for Quality of Life Science QUVI, University of Bologna, I-47921 Rimini, Italy; ${ }^{4}$ Division of Burns, Department of Surgery, Massachusetts General Hospital and Shriners Burns Institute, Harvard Medical School; ${ }^{5}$ Molecular Surgery Laboratory,

Department of Surgery, Massachusetts General Hospital, Boston, MA 02114, USA
\end{abstract}

Received July 15, 2013; Accepted September 3, 2013

DOI: 10.3892/ijmm.2014.1757

\begin{abstract}
In vivo nuclear magnetic resonance spectroscopy (NMR), a non-destructive biochemical tool used for investigating live organisms, has recently been performed in studies of the fruit fly Drosophila melanogaster, a useful model organism for investigating genetics and physiology. We used a novel high-resolution magic angle-spinning (HRMAS) NMR method to investigate live Drosophila GST2 mutants using a conventional 14.1-T NMR spectrometer equipped with an HRMAS probe. The results showed that, compared to wild-type (wt) controls, the GST2 mutants had a $48 \%$ greater $\left(\mathrm{CH}_{2}\right) \mathrm{n}$ lipid signal at $1.33 \mathrm{ppm}$, which is an insulin resistance biomarker in Drosophila skeletal muscle $(\mathrm{P}=0.0444)$. The mutants also had a $57 \%$ greater $\mathrm{CH}_{2} \mathrm{C}=$ lipid signal at $2.02 \mathrm{ppm}(\mathrm{P}=0.0276)$ and a $100 \%$ greater $-\mathrm{CH}=\mathrm{CH}$ - signal at
\end{abstract}

Correspondence to: Dr A. Aria Tzika, NMR Surgical Laboratory, Department of Surgery, Massachusetts General Hospital and Shriners Burn Institute, Harvard Medical School, 51 Blossom Street, Room 261, Boston, MA 02114, USA

E-mail: atzika@hms.harvard.edu

Abbreviations: Ac, acetate; $a k h r$, adipokinetic hormone receptor; $\beta$-Ala, $\beta$-alanine; CPMG, Carr-Purcell-Meiboom-Gill; Cho, choline; EMCLs, extramyocellular lipids; FFA, free fatty acids; HRMAS, high-resolution magic angle spinning; IMCLs, intramyocellular lipids; Lip, lipids; PUFA, poly-unsaturated fatty acid; TGA, triglycerides; wt, wild-type

Key words: magnetic resonance spectroscopy, high-resolution magic angle spinning, Drosophila melanogaster, GST2 mutation, biomarkers, insulin signaling, insulin resistance, apoptosis
$5.33 \mathrm{ppm}(\mathrm{P}=0.0251)$. Since the $-\mathrm{CH}=\mathrm{CH}$ - signal encompasses protons from ceramide, this latter difference is consistent with the hypothesis that the GST2 mutation is associated with insulin resistance and apoptosis. The findings of this study corroborate our previous results, support the hypothesis that the GST2 mutation is associated with insulin signaling and suggest that the IMCL level may be a biomarker of insulin resistance. Furthermore, direct links between GST2 mutation (the Drosophila ortholog of the GSTA4 gene in mammals) and insulin resistance, as suggested in this study, have not been made previously. These findings may thus be directly relevant to a wide range of metabolically disruptive conditions, such as trauma, aging and immune system deficiencies, that lead to increased susceptibility to infection.

\section{Introduction}

High-resolution magic angle spinning (HRMAS) nuclear proton magnetic resonance spectroscopy ('H NMR) is a novel non-destructive technique that substantially improves spectral line-widths and allows high-resolution spectra to be obtained from intact cells, cultured tissues $(1,2)$ and unprocessed tissues (3-7). HRMAS ${ }^{1} \mathrm{H}$ NMR enables us to investigate relationships between metabolites and cell processes. For example, choline (Cho)-containing compounds involved in phospholipid metabolism and lipids, such as triglycerides, that are involved in apoptosis have been studied (8-11). Nevertheless, HRMAS ${ }^{1} \mathrm{H}-\mathrm{NMR}$ has only been performed ex vivo thus far.

Studies combining in vivo ${ }^{1} \mathrm{H}$ NMR with ex vivo HRMAS ${ }^{1} \mathrm{H}$ NMR have demonstrated an important functional role of intramyocellular lipids (IMCLs) in rodent burn biology $(11,12)$, while other ex vivo HRMAS ${ }^{1} \mathrm{H}$ NMR studies have focused on lipid metabolism (13). Szczepaniak et al demonstrated that IMCL stores could be quantified accurately in a clinical setting by in vivo ${ }^{1} \mathrm{H}$ NMR (14). In a recently published ${ }^{1} \mathrm{H}$ 
NMR study, Van der Graaf et al found an inverse correlation between IMCL content in human calf muscle and local glycogen synthesis rate (15). Jacob et al emphasized the importance of these resonances as biomarkers of insulin resistance in type-2 diabetes patients and their offspring (16). Additionally, IMCL content was found to be increased in the soleus muscle of insulin-resistant elderly patients, providing support for the hypothesis that an age-associated decline in mitochondrial function contributes to insulin resistance (17).

In vivo HRMAS ${ }^{1} \mathrm{H}$ NMR is a potentially useful tool in Drosophila since in vitro NMR studies have shown the metabolic effects of hypoxia (18) and temperature stress (19) in flies. Although Drosophila is a distinctively useful model organism that can be employed to investigate genetics, physiology, and metabolism (20), with the exception of a recent feasibility report (21), in vivo NMR studies in Drosophila are lacking. Thus, we attempted to implement an in vivo HRMAS ${ }^{1} \mathrm{H}$ NMR method that we developed in Drosophila (22), with the aim of investigating the metabolism of Drosophila mutants. Such a study would be particularly useful for assessing the biomarkers of pathophysiology with the long-term goal of providing critical information that may direct novel therapeutic development.

State-of-the art, in vivo NMR techniques are used to elucidate metabolic patterns in Drosophila melanogaster as a model organism of interest owing to the notable parallels in the metabolism between Drosophila and mammals $(23,24)$. Indeed, the study of Drosophila metabolism is an emerging field that can potentially elucidate conserved metabolic mechanisms. Furthermore, the powerful genetic tools available in Drosophila research render the fruit fly a particularly tractable model organism in which to probe metabolic pathways and lead to a better understanding of human metabolic disorders.

Drosophila melanogaster glutathione S-transferase (GST2, also known as DmGSTS1-1) was recognized originally as an indirect flight muscle-associated protein with no known catalytic properties. In relation to mammalian GSTs, Drosophila GST2 is most similar to the sigma class of GSTs, and the mammalian GSTA4 gene is an ortholog of Drosophila GST2. In the present study, we investigated mutant flies that do not express the GST2 gene in skeletal muscle. We examined the feasibility of a novel, in vivo HRMAS ${ }^{1} \mathrm{H}$ NMR approach towards the investigation of the metabolic derangements in these GST2 mutant flies and compared them to isogenic control flies.

\section{Materials and methods}

Drosophila flies. Male Gst2 gene deletion flies (25), designated as GstS1M38 were used, and compared to male wild-type (wt) isogenic strain C5 flies. The two strains were kindly provided by Helen Benes (University of Arkansas). At the time of the experiments, all flies were 5-8 days of age and weighed $0.7-1.0 \mathrm{mg}$ ( $\mathrm{n}=6$ per group). Prior to insertion in the spectrometer, each fly was anesthetized by being placed on ice for $<1 \mathrm{~min}$. Flies were kept at $4^{\circ} \mathrm{C}$ while in the spectrometer.

In vivo HRMAS ${ }^{1} H$ NMR spectroscopy. All HRMAS ${ }^{1} \mathrm{H}$ NMR experiments were performed on a wide-bore Bruker Bio-Spin Avance NMR spectrometer (600.13 MHz) using a 4-mm triple resonance $\left({ }^{1} \mathrm{H},{ }^{13} \mathrm{C},{ }^{2} \mathrm{H}\right)$ HRMAS probe (Bruker, Billerica, MA, USA). The flies were placed into a zirconium oxide rotor tube ( $4 \mathrm{~mm}$ diameter, $50 \mu \mathrm{l}$ ), and $8 \mu \mathrm{l}$ of external standard trimethylsilyl-propionic-2,2,3,3-d4 acid (TSP) (molecular mass $=172 \mathrm{Da}, \mathrm{d}=0.00 \mathrm{ppm}, 50 \mathrm{mM}$ in $\mathrm{D}_{2} \mathrm{O}$ ) was introduced. TSP functioned as a reference for both resonance chemical shift and quantification. Each fly was placed in the rotor using the insert, which was sealed with a screw and covered with parafilm to prevent contact between the fly and the TSP/ $\mathrm{D}_{2} \mathrm{O}$ (Fig. 1). The samples were secured and tightened in the rotors with a top cap (Bruker). The HRMAS ${ }^{1} \mathrm{H}$ NMR was performed at $4^{\circ} \mathrm{C}$ with $2 \mathrm{kHz}$ MAS.

One dimensional (1D) water-suppressed spin-echo Carr-Purcell-Meiboom-Gill (CPMG) pulse sequencing $\left[90^{\circ}-\left(\tau-180^{\circ}-\tau\right)_{n}\right.$ - acquisition] (26) was performed on single flies. CPMG is a methodological improvement of particular interest in developing ex vivo 1D HRMAS of intact tissue samples since it suppresses broad signals that destroy the linear baseline in typical Free Induction Decay (FID) spectra. Thus, the CPMG proton NMR spectra are free from the broad component that contributes to the baseline of simple FID spectra. The CPMG sequence has also been applied to twodimensional sequences for the same reason.

Additional parameters for the CPMG sequence included an inter-pulse delay of $\tau=2 \pi / \omega_{\mathrm{r}}=250 \mathrm{msec}$, a total spin-echo delay of $30 \mathrm{msec}$, two total $180^{\circ}$ cycles, 256 transients, a spectral width of $7.2 \mathrm{kHz}, 32,768$ (32k) data points, and a $3-\mathrm{sec}$ relaxation time. A spin-echo delay of $30 \mathrm{msec}$ was chosen based on the observation that at this echo time, line broadening without loss of signal from triglycerides was avoided. When the spin-echo delay was increased, all the lipid signals were affected, but not in favor of other metabolites.

In vivo ${ }^{1} H$ HRMAS NMR data processing. MR spectra of specimens were analyzed using MestReC software (Mestrelab Research, www.mestrec.com). A $0.5-\mathrm{Hz}$ line-broadening apodization function was applied to CPMG HRMAS ${ }^{1} \mathrm{H}$ FIDs prior to Fourier transformation. MR spectra were referenced with respect to TSP at $\delta=0.0 \mathrm{ppm}$ (external standard), manually phased, and a Whittaker baseline estimator was applied to subtract the broad components of the baseline.

Quantification of metabolites from $1 D^{1} \mathrm{H} C P M G$ HRMAS spectra. For metabolite quantification from $1 \mathrm{D}{ }^{1} \mathrm{H}$ CPMG HRMAS spectra, we used the highly accurate 'external standard' technique. Metabolite concentrations were calculated using MestReC software. An automated fitting routine based on the Levenberg-Marquardt $(27,28)$ algorithm was applied after manual peak selection; peak positions, intensities, line widths, and Lorentzian/Gaussian ratios were adjusted until the residual spectrum was minimized. Metabolite concentration ( $\mathrm{mol} / \mathrm{kg}$ ) was calculated using the equation (29): $\operatorname{mass}_{\mathrm{TSP}} / \mathrm{PM}_{\mathrm{TSP}} \times \mathrm{Met}_{\text {(area) }} / \mathrm{TSP}_{\text {(area) }}$ × $\mathrm{N}_{\mathrm{TSP}} / \mathrm{N}_{\text {Met }}$ × $1 / \mathrm{wt}_{\text {(sample) }}$, where mass ${ }_{\mathrm{TSP}}$ was constant $(0.069 \mathrm{mg}), \mathrm{PM}_{\mathrm{TSP}}$ was the molar mass of TSP (172.23 g/mol), Met signifies metabolites, $\mathbf{N}_{\text {TSP }}$ was the TSP proton number $\left(9{ }^{1} \mathrm{H}\right), \mathrm{N}_{\text {Met }}$ was the metabolite proton number, and $\mathrm{wt}_{(\text {(sample) }}$ was the sample weight in $\mathrm{mg}(29)$.

Statistical analysis. Group data were compared with the Student's t-test. A P-value of 0.05 (corrected) was accepted as significant and all P-values are reported to two significant digits. Calculations were performed using SPSS (SPSS 12, SPSS Inc). 

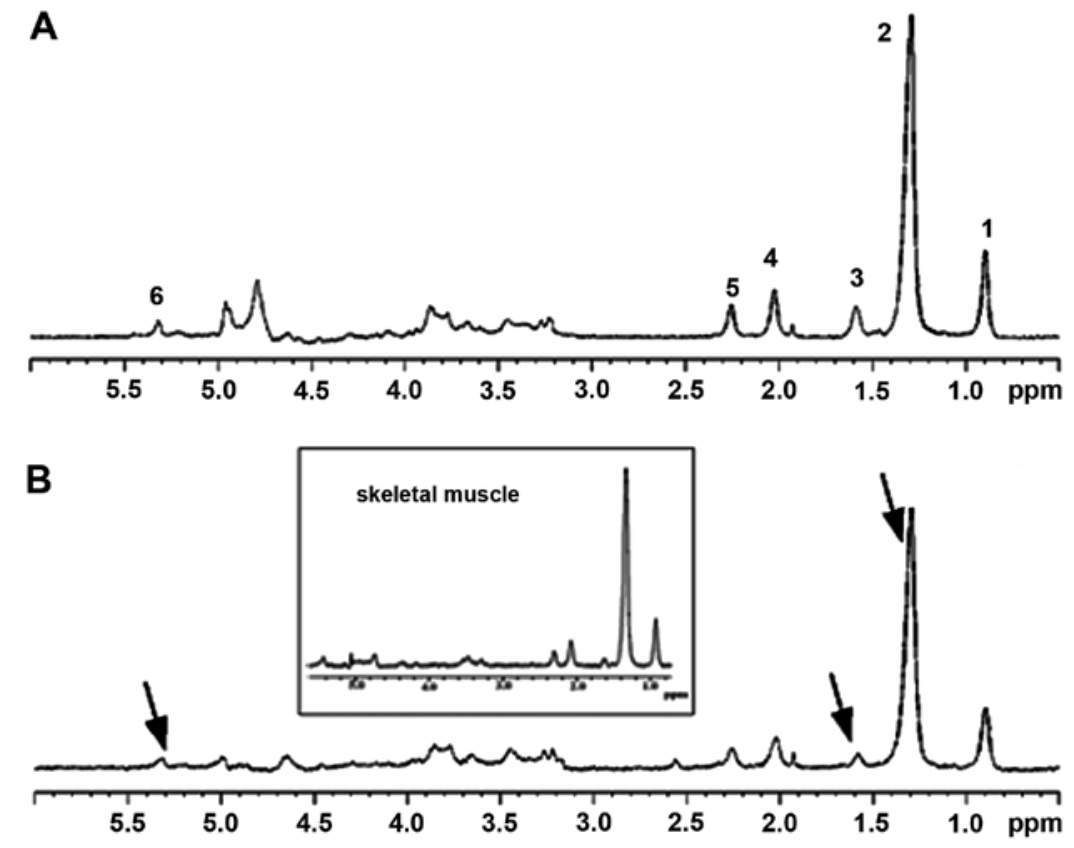

Figure 1. In vivo 1D HRMAS ${ }^{1} \mathrm{H}$ CPMG spectra of: (A) GST2 and (B) young wt flies. Lipid components were: $1, \mathrm{CH}_{3}(0.89 \mathrm{ppm}) ; 2,\left(\mathrm{CH}_{2}\right) \mathrm{n}(1.33 \mathrm{ppm}$, putative IMCLs); $3, \mathrm{CH}_{2} \mathrm{C}-\mathrm{CO}(1.58 \mathrm{ppm}$, putative EMCLs), acetate (Ac, $1.92 \mathrm{ppm}) ; 4, \mathrm{CH}_{2} \mathrm{C}=\mathrm{C}(2.02 \mathrm{ppm}) ; 5, \mathrm{CH}_{2} \mathrm{C}=\mathrm{O}(2.24 \mathrm{ppm}) ;$ and $6, \mathrm{CH}=\mathrm{CH}(5.33 \mathrm{ppm})$. Other spectral components included: $\beta$-alanine ( $\beta$-Ala, $2.55 \mathrm{ppm}$ ), phosphocholine (PC, $3.22 \mathrm{ppm})$, phosphoethanolamine (PE, $3.22 \mathrm{ppm})$, and glycerol (4.10,

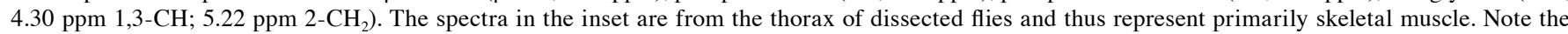
similarity of spectra for the dissected and whole flies. The spectra shown were normalized to TSP at each echo time and therefore do not exhibit a T2 decay. HRMAS, high-resolution magic angle spinning; wt, wild-type; IMCLs, intramyocellular lipids; EMCLs, extramyocellular lipids.

\section{Results and Discussion}

In the present study, we detected and quantified lipids and small metabolites in live Drosophila using ${ }^{1} \mathrm{H}$ HRMAS NMR at $14.1 \mathrm{~T}$ (Fig. 1) (30). All the flies survived the procedure, which was completed in $\sim 45$ min per fly. Our results confirmed our expectations in that we were able to reduce acquisition time, and thereby achieve zero mortality. We employed a novel in vivo HRMAS ${ }^{1} \mathrm{H}$ NMR approach in Drosophila to examine the hypothesis that the GST2 mutation results in insulin resistance, due to a phylogenetically conserved pathway for the regulation of glucose and lipid metabolism between flies and mammals $(31,32)$.

Drosophila was utilized in this study because, relative to other animal models, flies are inexpensive and easy to maintain and manipulate, and they have a well-known genome as well as numerous available mutants. These characteristics make Drosophila an ideal genetically amenable model organism with which to investigate the physiology of biomedical paradigms. To this end, invertebrate Drosophila models have already provided powerful experimental systems for muscle developmental biology investigations (33-35), age-related decline in function (36), such as neurodegeneration (37) and loss of immune $(38,39)$ and cardiac $(40)$ functions, and specifically, regarding muscle degeneration, for the investigation of protein synthesis $(41,42)$, sarcomere integrity (43-45), apoptosis (46), mitochondrial function and morphology $(44,45,47-50)$, stress response (48,51), glycogen content (45), muscle function and morphology (52,53), flight ability (54) (flight) myofiber stiffness and power $(44)$, and protein modifications $(55,56)$ and related transcriptional changes $(48,57,58)$. The conservation of insulin signaling between flies and mammals (31) renders Drosophila a particularly interesting model organism for metabolism studies. The focus of the present study on Drosophila as a model organism distinguishes this study from traditional metabolism experiments. The findings of this study are supported by findings in mammals showing evidence of insulin resistance and mitochondrial dysfunction in $m$ Gsta 4 null mice (59).

The in vivo fly spectra (see representative spectra in Fig. 1) of this study compare well to other published in vivo skeletal muscle spectra $(11,60,61)$. All of these studies have shown high amounts of lipids in skeletal muscle, particularly triglycerides. Other HRMAS reports involving skeletal muscle showed spectra with more metabolites than those of the present study $(8,62)$. The samples and set conditions in our experiments differed from those of prior studies in that we had a smaller quantity of sample $(0.6-1.1 \mathrm{mg})$ and we performed the experiment with a lower spin rate, which may have limited spectral resolution. The NMR-visible non-lipid components are expected to contribute only a small percentage in the total signal from sample flies, which are of extremely small size (0.7-0.8 mg total body weight), with concomitantly low sensitivity of detection. Even spectra from the thorax of dissected flies, which is highly enriched in skeletal muscle, are similar to whole fly spectra (inset of Fig. 1). Nevertheless, we were still able to detect certain metabolites from the 1D experiment (Fig. 1).

From a biomedical perspective, the principal finding of our experiments was that the GST2 mutation was associated with an accumulation of mobile lipids in muscle tissue. The quantitative data of selected components (triglycerides) detected in live Drosophila with HRMAS ${ }^{1} \mathrm{H}$ NMR are summarized in Table I. Fig. 2 (30) shows a bar graph of the amounts of the same selected components. There was a marked and signifi- 
Table I. Quantity of selected lipid components in live Drosophila according to ${ }^{1} \mathrm{H}$ HRMAS NMR (n=6/group).

\begin{tabular}{lccccc}
\hline & & \multicolumn{2}{c}{ Mean quantity $\pm \mathrm{SE}(\mu \mathrm{mol} / \mathrm{g})$} & & \\
\cline { 3 - 6 } Peak no. $(\mathrm{ppm})^{\mathrm{a}}$ & Lipid & $\mathrm{wt}$ & $G S T 2$ & \% difference & P-value \\
\hline $1(0.89)$ & $\mathrm{CH}_{3}$ & $0.12 \pm 0.02$ & $0.17 \pm 0.03$ & +41.7 & 0.1342 \\
$2(1.33)$ & $\left(\mathrm{CH}_{2}\right)_{\mathrm{n}}$ & $0.67 \pm 0.09$ & $0.99 \pm 0.13$ & +47.7 & $0.0444^{\mathrm{b}}$ \\
$3(1.58)$ & $\mathrm{CH}_{2} \mathrm{CCO}$ & $0.03 \pm 0.01$ & $0.07 \pm 0.02$ & +133.3 & 0.0748 \\
$4(2.02)$ & $\mathrm{CH}_{2} \mathrm{C}=\mathrm{C}$ & $0.07 \pm 0.01$ & $0.11 \pm 0.01$ & +57.1 & $0.0276^{\mathrm{b}}$ \\
$5(2.24)$ & $\mathrm{CH}_{2} \mathrm{CO}=\mathrm{O}$ & $0.05 \pm 0.01$ & $0.05 \pm 0.02$ & 0 & 0.4676 \\
$6(5.33)$ & $\mathrm{CH}=\mathrm{CH}$ & $0.02 \pm 0.004$ & $0.04 \pm 0.005$ & +100 & $0.0251^{\mathrm{b}}$ \\
\hline
\end{tabular}

${ }^{1} \mathrm{H}$ HRMAS NMR, ${ }^{1} \mathrm{H}$ high resolution magic angle spinning nuclear magnetic resonance spectroscopy; ${ }^{\mathrm{C}} \mathrm{Chemical}$ shifts are in parts per million

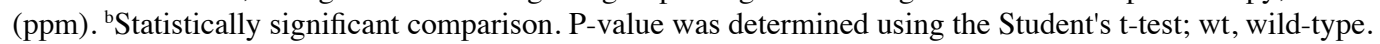

cant increase in $\left(\mathrm{CH}_{2}\right) \mathrm{n}(1.33 \mathrm{ppm})$ in the mutants relative to the wt controls. Additionally, we observed a trend towards more $\mathrm{CH}_{2} \mathrm{C}$-CO lipids (1.58 ppm) in the mutants (Table I).

Although determining the source of these accumulated lipids is beyond the scope of this study, it should be considered that extramyocellular lipids (EMCLs), IMCLs, and triglycerides can all contribute to cellular lipid peaks $(14,63,64)$. Specifically, EMCLs and IMCLs can be distinguished by in vivo NMR by differences in their bulk magnetic susceptibilities and geometric arrangements (65), with 1.33 ppm lipids, $\left(\mathrm{CH}_{2}\right) \mathrm{n}$, being attributed to IMCLs and $1.58 \mathrm{ppm}$ lipids, $\mathrm{CH}_{2} \mathrm{C}-\mathrm{CO}$, being attributed to EMCLs. However, discrimination is not likely in the present study. Spinning a sample at the magic angle (HRMAS) with respect to the static field direction averages the second-order tensors of the anisotropic chemical shift, the dipolar interaction, and the susceptibility variations in heterogeneous samples (66-68). Garroway (67) indicated that MAS eliminates the broadening effect produced by magnetic susceptibility, and eliminates the shift itself. In their study, Chen et al (69) clarified that, irrespective of system geometry, MAS eliminates only the anisotropic contribution of bulk susceptibility inside a homogeneous susceptibility region. Inspecting the isotropic part of the susceptibility tensors available for IMCLs and EMCLs (63,70), we can deduce that IMCLs and EMCLs have an identical chemical shift under MAS conditions due to bulk susceptibility.

IMCLs probably serve as an energy substrate for oxidative metabolism (71), and can be mobilized and utilized with turnover times in the range of several hours (72). In insects, triglycerides are located in body fat. Triglycerides in insect body fat (73-75) are used for storage of both energy and fatty acid precursors, such as transported lipids, phospholipids (membrane structure), hydrocarbons, and wax esters (that minimize water loss from the cuticle due to evaporation) (76). In our study, mobility of fat body contents may have been affected by trauma or immune status, leading to strong IMCL and EMCL signals (77). However, this suggestion is only hypothetical as the intracellular signaling cascade mediating mobilization of triglycerides has not been as fully elucidated in insects as it has in mammals (78). Nevertheless, we suggest that there was mobilization of triglycerides in the $G S T 2^{-/-}$flies because the peaks indicative of triglycerides at 1.33 and $1.58 \mathrm{ppm}$ were increased (79). The significantly greater triglyceride signals

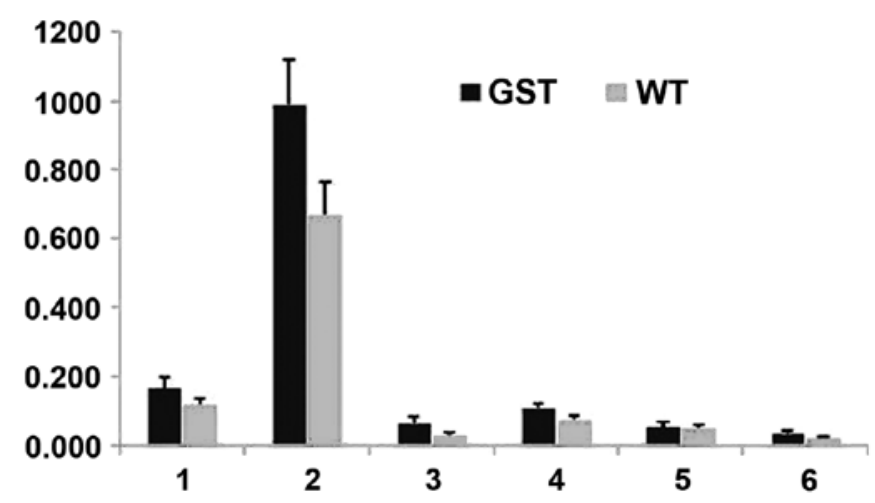

Figure 2. Lipid quantities calculated from in vivo $1 \mathrm{D}$ HRMAS ${ }^{1} \mathrm{H}$ CPMG spectra of young wt flies (light gray) and GST2 mutant flies (black). 1, $\mathrm{CH}_{3}$ $(0.89 \mathrm{ppm}) ; 2,\left(\mathrm{CH}_{2}\right) \mathrm{n}(1.33 \mathrm{ppm})$ or IMCLs; $3, \mathrm{CH}_{2} \mathrm{C}-\mathrm{CO}(1.58 \mathrm{ppm})$ or EMCLs; 4, $\mathrm{CH}_{2} \mathrm{C}=\mathrm{C}(2.02 \mathrm{ppm}) ; 5, \mathrm{CH}_{2} \mathrm{C}=\mathrm{O}(2.24 \mathrm{ppm}) ; 6, \mathrm{CH}=\mathrm{CH}$ (5.33 ppm). HRMAS, high-resolution magic angle spinning; wt, wild-type; IMCLs, intramyocellular lipids; EMCLs, extramyocellular lipids.

(both IMCLs and EMCLs) detected in the $G S T 2^{-/}$mutants vs. wt controls (Figs. 1 and 2, Table I) resembles the metabolic profile of $a k h r$ flies with an obese phenotype and abnormal accumulation of both lipids and carbohydrates (79). Specifically, elevated IMCL levels are associated with insulin resistance, a major metabolic dysfunction of diabetes, aging $(80,81)$, burn trauma $(82,83)$ and obesity $(84-87)$.

Moreover, our observations of increased peaks indicative of triglycerides at $1.33 \mathrm{ppm}$ in $G S T 2^{-/}$flies agree with prior findings in chico flies (79) with disrupted insulin signaling. Chico flies have a mutated insulin receptor substrate (IRS) gene, a Drosophila homolog of vertebrate IRS1-4. Chico flies have a small stature and show abnormally high triglyceride levels $(88,89)$ that are attributable to a dysfunctional mutated insulin signaling pathway (31), resulting in insulin resistance. The high $1.33 \mathrm{ppm}$ peak in chico flies is clearly due to IMCLs and not to EMCLs since these flies are not obese. Accordingly, chico flies do not exhibit significantly increased $1.58 \mathrm{ppm}$ peaks, which are frequently attributed to EMCLs (79). Thus, despite the theoretical considerations of HRMAS, it remains likely that the lipids that produce the peak at $1.33 \mathrm{ppm}$ are primarily IMCLs, whereas the lipids that yield a peak at 
1.58 ppm are primarily EMCLs. Thus, chico flies are a suitable comparison strain for GST2 flies, which also exhibit increased triglycerides, evidently due to increased IMCLs since they are not obese, and thus not expected to have increased EMCLs. Conversely, $a k h r$ flies exhibit a metabolic profile with significantly increased peaks in all assigned lipids, agrees with their obese phenotype (79).

Another principal finding of our experiments was that peaks $4\left(\mathrm{CH}_{2} \mathrm{C}=\mathrm{C}\right.$ at $\left.2.02 \mathrm{ppm}\right)$ and $6(\mathrm{CH}=\mathrm{CH}$ at $5.33 \mathrm{ppm})$, which includes protons from ceramide, were also significantly increased in the mutant flies compared to wt controls (Table I and Fig. 2). Ceramide accumulation decreases insulin-stimulated GLUT4 translocation to the plasma membrane and, consequently, reduces glucose transport (90), resulting in insulin resistance. Paumen and co-workers demonstrated that saturated fatty acids such as palmitoleic acid at $2.02 \mathrm{ppm}$ in our study, induce de novo synthesis of ceramide and programmed cell death (90). They suggested that inhibition of carnitine palmitoyltransferase I activity induces both sphingolipid synthesis and palmitate-induced cell death. Ruddock et al (91) suggested that long-chain saturated fatty acids (palmitoleic acid C16:0) attenuate insulin signal transduction in hepatoma cell lines. Their study suggests that an increase in palmitoleic acid signifies insulin resistance. If this is the case, then the signal at $2.02 \mathrm{ppm}$ in our study may also be a biomarker of insulin resistance; this peak was elevated in our GST2 $2^{-/-}$flies $\left(\mathrm{CH}_{2} \mathrm{C}=\mathrm{C}\right.$ at 2.02 ppm, peak 4 in Figs. 1 and 2) and in chico flies (79).

From a biomedical perspective, the findings of this study support the hypothesis that the GST2 mutation is associated with insulin signaling and suggest that the IMCL level may be a biomarker of insulin resistance in $G S T 2^{-/-}$flies. However, whether IMCLs are directly involved in the development of insulin resistance simply serve as an indirect marker is currently a topic of debate (92). Insulin resistance has not been demonstrated previously in flies with currently available assays. Furthermore, direct links between GST2 mutation (the Drosophila ortholog of the GSTA4 gene in mammals) and insulin resistance, as suggested in this study, have not been made previously. The common characteristics shared among innate immunity activation, obesity, and insulin resistance, as recently described (79), support the findings of this study.

In conclusion, findings of the present study have demonstrated that a novel solid-state HRMAS NMR method is a sensitive tool for the molecular characterization of metabolic perturbations in Drosophila. We observed increased levels of triglycerides in GST2 $2^{-/-}$Drosophila mutant that may be indicative of insulin resistance. These findings may thus be directly relevant to the mitochondrial dysfunction that occurs in a wide range of metabolically disruptive conditions, such as trauma, aging, and immune system deficiencies, that lead to elevated susceptibility to infection. Our findings advance the development of novel in vivo non-destructive research approaches in Drosophila strains, offers biomarkers to investigate biomedical paradigms, and thus may direct novel therapeutic development.

\section{Acknowledgements}

This study was supported in part by a grant from DM103014 of the Defense Medical Research and Development Program
(DMRDP) to Laurence G. Rahme (A. Aria Tzika, co-investigator). We would like to thank Professor Helen Benes of the University of Arkansas for Medical Sciences for providing the Drosophilas used in this study. We would also like to thank Dr Ann Power Smith (Write Science Right, Las Vegas, NV, USA) for editorial assistance.

\section{References}

1. Weybright P, Millis K, Campbell N, Cory DG and Singer S: Gradient, high-resolution, magic angle spinning ${ }^{1} \mathrm{H}$ nuclear magnetic resonance spectroscopy of intact cells. Magn Reson Med 39: 337-345, 1998 .

2. Blankenberg FG, Storrs RW, Naumovski L, Goralski T and Spielman D: Detection of apoptotic cell death by proton nuclear magnetic resonance spectroscopy. Blood 87: 1951-1956, 1996.

3. Cheng LL, Ma MJ, Becerra L, et al: Quantitative neuropathology by high resolution magic angle spinning proton magnetic resonance spectroscopy. Proc Natl Acad Sci USA 94: 6408-6413, 1997.

4. Cheng LL, Newell K, Mallory AE, Hyman BT and Gonzalez RG: Quantification of neurons in Alzheimer and control brains with ex vivo high resolution magic angle spinning proton magnetic resonance spectroscopy and stereology. Magn Reson Imaging 20: 527-533, 2002.

5. Millis KK, Maas WE, Cory DG and Singer S: Gradient, highresolution, magic-angle spinning nuclear magnetic resonance spectroscopy of human adipocyte tissue. Magn Reson Med 38: 399-403, 1997.

6. Millis K, Weybright P, Campbell N, et al: Classification of human liposarcoma and lipoma using ex vivo proton NMR spectroscopy. Magn Reson Med 41: 257-267, 1999.

7. Barton SJ, Howe FA, Tomlins AM, et al: Comparison of in vivo ${ }^{1} \mathrm{H}$ MRS of human brain tumours with ${ }^{1} \mathrm{H}$ HR-MAS spectroscopy of intact biopsy samples in vitro. MAGMA 8: 121-128, 1999.

8. Griffin JL, Williams HJ, Sang E and Nicholson JK: Abnormal lipid profile of dystrophic cardiac tissue as demonstrated by one- and two-dimensional magic-angle spinning (1)H NMR spectroscopy. Magn Reson Med 46: 249-255, 2001.

9. Tzika AA, Cheng LL, Goumnerova L, et al: Biochemical characterization of pediatric brain tumors by using in vivo and ex vivo magnetic resonance spectroscopy. J Neurosurg 96: 1023-1031, 2002.

10. Tugnoli V, Schenetti L, Mucci A, et al: Ex vivo HR-MAS MRS of human meningiomas: a comparison with in vivo ${ }^{1} \mathrm{H}$ MR spectra. Int J Mol Med 18: 859-869, 2006.

11. Astrakas LG, Goljer I, Yasuhara S, et al: Proton NMR spectroscopy shows lipids accumulate in skeletal muscle in response to burn trauma-induced apoptosis. FASEB J 19: 1431-1440, 2005.

12. Tzika AA, Astrakas LG, Cao H, et al: Murine intramyocellular lipids quantified by NMR act as metabolic biomarkers in burn trauma. Int J Mol Med 21: 825-832, 2008.

13. Bollard ME, Garrod S, Holmes E, et al: High-resolution (1)H and (1) $\mathrm{H}-(13) \mathrm{C}$ magic angle spinning NMR spectroscopy of rat liver. Magn Reson Med 44: 201-207, 2000.

14. Szczepaniak LS, Babcock EE, Schick F, et al: Measurement of intracellular triglyceride stores by $\mathrm{H}$ spectroscopy: validation in vivo. Am J Physiol 276: E977-E989, 1999.

15. van der Graaf M, Tack CJ, de Haan JH, Klomp DW and Heerschap A: Magnetic resonance spectroscopy shows an inverse correlation between intramyocellular lipid content in human calf muscle and local glycogen synthesis rate. NMR Biomed 23: 133-141, 2009.

16. Jacob S, Machann J, Rett K, et al: Association of increased intramyocellular lipid content with insulin resistance in lean nondiabetic offspring of type 2 diabetic subjects. Diabetes 48: 1113-1119, 1999.

17. Petersen KF, Befroy D, Dufour S, et al: Mitochondrial dysfunction in the elderly: possible role in insulin resistance. Science 300: 1140-1142, 2003.

18. Feala JD, Coquin L, McCulloch AD and Paternostro G: Flexibility in energy metabolism supports hypoxia tolerance in Drosophila flight muscle: metabolomic and computational systems analysis. Mol Syst Biol 3: 99, 2007.

19. Pedersen KS, Kristensen TN, Loeschcke V, et al: Metabolomic signatures of inbreeding at benign and stressful temperatures in Drosophila melanogaster. Genetics 180: 1233-1243, 2008.

20. Bharucha KN: The epicurean fly: using Drosophila melanogaster to study metabolism. Pediatr Res 65: 132-137, 2009. 
21. Null B, Liu CW, Hedehus M, Conolly S and Davis RW: Highresolution, in vivo magnetic resonance imaging of Drosophila at 18.8 Tesla. PLoS One 3: e2817, 2008.

22. Righi V, Apidianakis Y, Rahme LG and Tzika AA: Magnetic resonance spectroscopy of live Drosophila melanogaster using magic angle spinning. J Vis Exp 38: 1710, 2010.

23. Baker KD and Thummel CS: Diabetic larvae and obese fliesemerging studies of metabolism in Drosophila. Cell Metab 6: 257-266, 2007.

24. Leopold P and Perrimon N: Drosophila and the genetics of the internal milieu. Nature 450: 186-188, 2007.

25. Singh SP, Coronella JA, Benes H, Cochrane BJ and Zimniak P: Catalytic function of Drosophila melanogaster glutathione S-transferase DmGSTS1-1 (GST-2) in conjugation of lipid peroxidation end products. Eur J Biochem 268: 2912-2923, 2001

26. Meiboom S and Gill D: Modified spiin-echo method for measuring nuclear relaxation time. Rev Sci Instrum 29: 688-691, 1958.

27. Levenberg K: A method for the solution of certain non-linear problems in least squares. Q Appl Math 2: 164-168, 1944.

28. Marquardt D: An algorithm for least-squares estimation of nonlinear parameters. SIAM J Appl Math 11: 431-441, 1963.

29. Swanson MG, Zektzer AS, Tabatabai ZL, et al: Quantitative analysis of prostate metabolites using ${ }^{1} \mathrm{H}$ HR-MAS spectroscopy. Magn Reson Med 55: 1257-1264, 2006.

30. Righi V, Apidianakis Y, Psychogios N, Rahme LG, Tompkins RG and Tzika AA: In vivo high-resolution magic angle spinning proton NMR spectroscopy of Drosophila melanogaster flies as a model system to investigate mitochondrial dysfunction in Drosophila mutants. Intl Soc Mag Reson Med 1460: 19, 2011.

31. Garofalo RS: Genetic analysis of insulin signaling in Drosophila. Trends Endocrinol Metab 13: 156-162, 2002.

32. Saltiel AR and Kahn CR: Insulin signalling and the regulation of glucose and lipid metabolism. Nature 414: 799-806, 2001.

33. Abmayr SM, Zhuang S and Geisbrecht ER: Myoblast fusion in Drosophila. Methods Mol Biol 475: 75-97, 2008.

34. Richardson B, Beckett K and Baylies M: Visualizing new dimensions in Drosophila myoblast fusion. Bioessays 30: 423-431, 2008.

35. Rochlin K, Yu S, Roy S and Baylies MK: Myoblast fusion: when it takes more to make one. Dev Biol 341: 66-83, 2010.

36. Partridge L and Tower J: Yeast, a feast: The fruit fly Drosophila as a model organism for research into aging. In: The Molecular Biology of Aging. Guarente L and Partridge L (eds.). Cold Spring Harbor Laboratory Press, pp267-308, 2008

37. Marsh JL and Thompson LM: Drosophila in the study of neurodegenerative disease. Neuron 52: 169-178, 2006.

38. Ramsden S, Cheung YY and Seroude L: Functional analysis of the Drosophila immune response during aging. Aging Cell 7 : 225-236, 2008.

39. Zerofsky M, Harel E, Silverman N and Tatar M: Aging of the innate immune response in Drosophila melanogaster. Aging Cell 4: 103-108, 2005

40. Ocorr K, Akasaka T and Bodmer R: Age-related cardiac disease model of Drosophila. Mech Ageing Dev 128: 112-116, 2007.

41. Smith JM, Bozcuk AN and Tebbutt S: Protein turnover in adult Drosophila. J Insect Physiol 16: 601-613, 1970.

42. Webster GC, Beachell VT and Webster SL: Differential decrease in protein synthesis by microsomes from aging Drosophila melanogaster. Exp Gerontol 15: 495-497, 1980.

43. Gartner LP: Aging and the visceral musculature of the adult fruitfly: an ultrastructural investigation. Trans Am Microsc Soc 96: 48-55, 1977.

44. Miller MS, Lekkas P, Braddock JM, et al: Aging enhances indirect flight muscle fiber performance yet decreases flight ability in Drosophila. Biophys J 95: 2391-2401, 2008.

45. Takahashi A, Philpott DE and Miquel J: Electron microscope studies on aging Drosophila melanogaster. 3. Flight muscle. J Gerontol 25: 222-228, 1970.

46. Zheng J, Edelman SW, Tharmarajah G, Walker DW, Pletcher SD and Seroude L: Differential patterns of apoptosis in response to aging in Drosophila. Proc Natl Acad Sci USA 102: 12083-12088, 2005 .

47. Ferguson M, Mockett RJ, Shen Y, Orr WC and Sohal RS: Age-associated decline in mitochondrial respiration and electron transport in Drosophila melanogaster. Biochem J 390: 501-511, 2005 .

48. Girardot F, Lasbleiz C, Monnier V and Tricoire H: Specific age-related signatures in Drosophila body parts transcriptome. BMC Genomics 7: 69, 2006.
49. Magwere T, Goodall S, Skepper J, Mair W, Brand MD and Partridge L: The effect of dietary restriction on mitochondrial protein density and flight muscle mitochondrial morphology in Drosophila. J Gerontol A Biol Sci Med Sci 61: 36-47, 2006.

50. Sohal RS, Sohal BH and Orr WC: Mitochondrial superoxide and hydrogen peroxide generation, protein oxidative damage, and longevity in different species of flies. Free Radic Biol Med 19: 499-504, 1995

51. Goddeeris MM, Cook-Wiens E, Horton WJ, et al: Delayed behavioural aging and altered mortality in Drosophila beta integrin mutants. Aging Cell 2: 257-264, 2003.

52. Miller BM, Zhang S, Suggs JA, et al: An alternative domain near the nucleotide-binding site of Drosophila muscle myosin affects ATPase kinetics. J Mol Biol 353: 14-25, 2005.

53. Kronert WA, Dambacher CM, Knowles AF, Swank DM and Bernstein SI: Alternative relay domains of Drosophila melanogaster myosin differentially affect ATPase activity, in vitro motility, myofibril structure and muscle function. J Mol Biol 379: 443-456, 2008

54. Kronert WA, Melkani GC, Melkani A and Bernstein SI: Mutating the converter-relay interface of Drosophila myosin perturbs ATPase activity, actin motility, myofibril stability and flight ability. J Mol Biol 398: 625-632, 2010.

55. Das N, Levine RL, Orr WC and Sohal RS: Selectivity of protein oxidative damage during aging in Drosophila melanogaster. Biochem J 360: 209-216, 2001.

56. Toroser D, Orr WC and Sohal RS: Carbonylation of mitochondrial proteins in Drosophila melanogaster during aging. Biochem Biophys Res Commun 363: 418-424, 2007.

57. Wheeler JC, Bieschke ET and Tower J: Muscle-specific expression of Drosophila hsp70 in response to aging and oxidative stress. Proc Natl Acad Sci USA 92: 10408-10412, 1995.

58. Zhan M, Yamaza H, Sun Y, Sinclair J, Li H and Zou S: Temporal and spatial transcriptional profiles of aging in Drosophila melanogaster. Genome Res 17: 1236-1243, 2007.

59. Singh SP, Niemczyk M, Saini D, Awasthi YC, Zimniak L and Zimniak P: Role of the electrophilic lipid peroxidation product 4-hydroxynonenal in the development and maintenance of obesity in mice. Biochemistry 47: 3900-3911, 2008.

60. Weis J, Johansson L, Ortiz-Nieto F and Ahlstrom H: Assessment of lipids in skeletal muscle by LCModel and AMARES. J Magn Reson Imaging 30: 1124-1129, 2009.

61. Wang L, Salibi N, Wu Y, Schweitzer ME and Regatte RR: Relaxation times of skeletal muscle metabolites at 7T. J Magn Reson Imaging 29: 1457-1464, 2009.

62. Chen JH, Sambol EB, Decarolis P, et al: High-resolution MAS NMR spectroscopy detection of the spin magnetization exchange by cross-relaxation and chemical exchange in intact cell lines and human tissue specimens. Magn Reson Med 55: 1246-1256, 2006.

63. Boesch C, Slotboom J, Hoppeler H and Kreis R: In vivo determination of intra-myocellular lipids in human muscle by means of localized ${ }^{1}$ H-MR-spectroscopy. Magn Reson Med 37: 484-493, 1997.

64. Vermathen P, Kreis R and Boesch C: Distribution of intramyocellular lipids in human calf muscles as determined by MR spectroscopic imaging. Magn Reson Med 51: 253-262, 2004.

65. Havel RJ, Carlson LA, Ekelund LG and Holmgren A: Turnover rate and oxidation of different free fatty acids in man during exercise. J Appl Physiol 19: 613-618, 1964.

66. Mehring M: High Resolution NMR in Solids. Springer-Verlag, New York, 1982

67. Garroway AN: Magic-angle sample spinning of liquids. J Magn Reson 49: 168-171, 1982.

68. Barbara TM: Cylindrical demagnetization fields and microprobe design in high resolution NMR. J Magn Reson A 109: 265, 1994.

69. Chen JH, Enloe BM, Xiao Y, Cory DG and Singer S: Isotropic susceptibility shift under MAS: the origin of the split water resonances in ${ }^{1} \mathrm{H}$ MAS NMR spectra of cell suspensions. Magn Reson Med 50: 515-521, 2003.

70. Chu SC, Xu Y, Balschi JA and Springer CS Jr: Bulk magnetic susceptibility shifts in NMR studies of compartmentalized samples: use of paramagnetic reagents. Magn Reson Med 13: 239-262, 1990.

71. Kayar SR, Hoppeler H, Howald H, Claassen H and Oberholzer F: Acute effects of endurance exercise on mitochondrial distribution and skeletal muscle morphology. Eur J Appl Physiol Occup Physiol 54: 578-584, 1986.

72. Canavoso LE, Jouni ZE, Karnas KJ, Pennington JE and Wells MA: Fat metabolism in insects. Annu Rev Nutr 21: 23-46, 2001. 
73. Gilby AR: Lipids and their metabolism in insects. Annu Rev Entomol 10: 141-160, 1965.

74. Fast PG: A comparative study of the phospholipids and fatty acids of some insect lipids. Science 155: 1680-1681, 1967.

75. Stanley-Samuelson DW, Jurenka RA, Cripps C, Blomquist GJ and deRenobales M: Fatty acids in insects: composition, metabolism, and biological significance. Arch Insect Biochem Physiol 9: $1-33,1988$.

76. Horne I, Haritos VS and Oakeshott JG: Comparative and functional genomics of lipases in holometabolous insects. Insect Biochem Mol Biol 39: 547-567, 2009.

77. Patel RT, Soulages JL, Hariharasundaram B and Arrese EL: Activation of the lipid droplet controls the rate of lipolysis of triglycerides in the insect fat body. J Biol Chem 280: 22624-22631, 2005.

78. Bharucha KN, Tarr P and Zipursky SL: A glucagon-like endocrine pathway in Drosophila modulates both lipid and carbohydrate homeostasis. J Exp Biol 211: 3103-3110, 2008.

79. Righi V, Apidianakis Y, Mintzopoulos D, Astrakas L, Rahme LG and Tzika AA: In vivo high-resolution magic angle spinning magnetic resonance spectroscopy of Drosophila melanogaster at $14.1 \mathrm{~T}$ shows trauma in aging and in innate immune-deficiency is linked to reduced insulin signaling. Int J Mol Med 26: 175-184, 2010.

80. Machann J, Thamer C, Schnoedt B, et al: Age and gender related effects on adipose tissue compartments of subjects with increased risk for type 2 diabetes: a whole body MRI/MRS study. MAGMA 18: 128-137, 2005.

81. Nakagawa Y, Hattori M, Harada K, Shirase R, Bando M and Okano G: Age-related changes in intramyocellular lipid in humans by in vivo H-MR spectroscopy. Gerontology 53: 218-223, 2007.

82. Muller MJ and Herndon DN: The challenge of burns. Lancet 343 : 216-220, 1994

83. Ikezu T, Okamoto T, Yonezawa K, Tompkins RG and Martyn JA Analysis of thermal injury-induced insulin resistance in rodents. Implication of postreceptor mechanisms. J Biol Chem 272: 25289-25295, 1997.
84. Sinha R, Dufour S, Petersen KF, et al: Assessment of skeletal muscle triglyceride content by (1)H nuclear magnetic resonance spectroscopy in lean and obese adolescents: relationships to insulin sensitivity, total body fat, and central adiposity. Diabetes 51: 1022-1027, 2002.

85. Schrauwen-Hinderling VB, Hesselink MK, Schrauwen P and Kooi ME: Intramyocellular lipid content in human skeletal muscle. Obesity (Silver Spring) 14: 357-367, 2006.

86. Consitt LA, Bell JA and Houmard JA: Intramuscular lipid metabolism, insulin action, and obesity. IUBMB Life 61: 47-55, 2009.

87. Johnson AB, Argyraki M, Thow JC, Cooper BG, Fulcher G and Taylor R: Effect of increased free fatty acid supply on glucose metabolism and skeletal muscle glycogen synthase activity in normal man. Clin Sci (Lond) 82: 219-226, 1992.

88. Clancy DJ, Gems D, Harshman LG, et al: Extension of life-span by loss of CHICO, a Drosophila insulin receptor substrate protein. Science 292: 104-106, 2001.

89. Bohni R, Riesgo-Escovar J, Oldham S, et al: Autonomous control of cell and organ size by CHICO, a Drosophila homolog of vertebrate IRS1-4. Cell 97: 865-875, 1999.

90. Paumen MB, Ishida Y, Muramatsu M, Yamamoto M and Honjo T: Inhibition of carnitine palmitoyltransferase I augments sphingolipid synthesis and palmitate-induced apoptosis. J Biol Chem 272: 3324-3329, 1997.

91. Ruddock MW, Stein A, Landaker E, et al: Saturated fatty acids inhibit hepatic insulin action by modulating insulin receptor expression and post-receptor signalling. J Biochem 144: 599-607, 2008.

92. Fernandez-Real JM and Pickup JC: Innate immunity, insulin resistance and type 2 diabetes. Trends Endocrinol Metab 19: 10-16, 2008. 